\title{
Constancio II, modelo de emperador cristiano en las Orationes IV y V de Gregorio de Nacianzo ${ }^{1}$
}

\author{
Ramón TEJA \\ Universidad de Cantabria \\ tejar@unican.es
}

« ¡Oh tú, el más divino de los emperadores y el más amante de Cristo (theiótate kaì philochristótate) [...] Has actuado llevado de la mano de Dios en todas tus acciones y decisiones; no sabría si admirar en ti más la fuerza o la inteligencia, pero, por encima de tu buena reputación en ambas, la piedad (eusebeia)» ${ }^{2}$. En este apóstrofe dirigido por Gregorio Nacianzeno a Constancio II, el obispo capadocio no sólo no manifiesta ningún escrúpulo en reconocer el carácter divino del emperador en la más pura tradición del paganismo romano, sino, también, lo que resulta más sorprendente aún, en ensalzarle como el más piadoso u ortodoxo de los emperadores cristianos, olvidando e ignorando su política religiosa a favor del arrianismo. En un artículo reciente ${ }^{3}$, después de recordar que el obispo capadocio presenta aquí a Constancio II como modelo de príncipe cristiano, me preguntaba «qué habrían pensado del credo profesado por Gregorio Nacianzeno un Hilario de Poitiers, un Lucifer de Cagliari, un Atanasio de Alejandría del que el capadocio fue más adelante panegirista, si hubieran escuchado estas alabanzas del considerado por ellos emperador arriano por antonomasia y encarnación del Anticristo».

La respuesta a esta pregunta debe buscarse en el género literario del que se sirvieron todos estos polemistas cristianos, a saber, la invectiva retórica de tan gran tradición en la literatura clásica, aunque, como ha señalado con acierto Luigi Lugaresi, las Orationes contra Juliano son originales, incluso en su forma literaria, non facilmente ascrivibile ad un genero preciso ${ }^{4}$. El elogio de Constancio forma parte de la primera de sus Invectivas contra Juliano, su Oratio IV, y tiene como objetivo contraponer la política religiosa del Apóstata con la de su predecesor, lo que determina, en palabras de Justin Mossay que les louanges addresées à Constance servent de repoussoir aux blâmes de toutes sortes qui accablent Julien: l'invective, contrepied de l'eloge,

\footnotetext{
${ }^{1}$ Este estudio ha sido desarrollado en el marco de los Proyectos de Investigación FFI2012-35686; y HAR 2010-15957.

${ }^{2}$ Greg. Naz., Oratio IV, 34 (ed. y tr.fr. J. Bernardi, Grégoire de Nazianze, Discours 4-5, Paris, 1983).

${ }^{3}$ R. Teja, «Constantino frente a Constancio II: la deformación de la memoria histórica entre "arrianos" y "nicenos», J. Vilella, (ed.), Constantinus: ¿el primer emperador cristiano? (Actas del Congreso Internacional, Barcelona 20-24 marzo 2012), en prensa.

${ }^{4}$ L. Lugaresi, Gregorio di Nazianzo. Contro Giuliano l'Apostata, Orazione IV, Firenze 1993, p.47
} 
applique à rebours les topiques de louange ${ }^{5}$. Por su parte, Jean Bernardi ha hecho ver que rhéteur de formation, Grégoire à appris à tout eclairer en function de l'unique but poursuivi et à se fier moins à la verité qu'a l'eikos 6 .

Hemos de tener muy presente a la hora de analizar el valor histórico de la Oratio IV y de la Oratio V, complemento, o segunda parte de la primera, que nos encontramos ante un opus rhetoricum, cuyo objetivo es la persuasión, y no ante un opus historicum, es decir, respetuoso con la verdad. La retórica terminó por impregnar en profundidad casi toda la literatura antigua, incluida la que se presenta bajo ropaje de objetividad como es el caso de la literatura histórica. Con buen criterio Luciano de Samosata criticaba a «aquellos que ignoran que la línea que divide la historia y el panegírico -podría haber añadido la diatriba- no es un istmo estrecho, sino que hay una gran muralla entre ellos» ${ }^{7}$. Pero no lo ignora el propio Gregorio cuando en la Orat. IV declara que dejará en manos de los libros de historia el cometido de narrar todas las acciones de Juliano pues él lo que se propone es dejar para la posteridad «una estela de su infamia» ${ }^{8}$. Y vuelve sobre el tema en lo que constituye una especie de recapitulación final de la Oratio V: «Esta es la estela que te dedico, más alta y expuesta a la vista de todos que las columnas de Hércules... Te estigmatiza a ti y a tus empresas para que todos aprendan a no cometer la audacia de rebelarse contra Dios» ${ }^{9}$. Por ello, los historiadores de hoy nos vemos obligados a someter casi todos los escritos que nos ha legado la Antigüedad, tanto clásica como cristiana, a una especie de análisis exegético para liberar de polémicas y apologías la objetividad que perseguimos. Lo ha resaltado con buen criterio, Ugo Criscuolo cuando escribe, a propósito de la Oratio IV, que «Gregorio è cosciente di voler perseguire con la sua Invectiva un intento politico e di voler evitare che essa sia intesa come testimonianza storica $\rangle^{10}$. Debemos preguntarnos, pues, qué objetivos perseguía el obispo capadocio, que pasaría a la historia con el sobrenombre de el Teólogo, cuando ensalza al emperador arriano Constancio II como modelo de emperador cristiano.

Gregorio comienza su discurso, escrito sólo pocos meses después de la muerte de Juliano, invitando a todas las gentes y habitantes de la ecumene a participar en la gran fiesta que significa el que haya sido abatido el Anticristo, que no era un tirano cualquiera, sino el Señor de toda la tierra habitada: «el dragón, el apóstata, el Asirio, el adversario común y enemigo de todos ${ }^{11}$. Después de esta invitación a la celebración universal, introduce a Constancio disfrutando de la gloria celestial porque la victoria, es decir, la muerte del tirano, ha sido obra de las potencias celestes que participan en la celebración del triunfo junto con el alma de Constancio, que es presentado, ya de entrada, como un príncipe más cristiano que todos los que le han precedido:

\footnotetext{
5 J. Mosssay, La mort et l'au-dela dans Saint Grégoire de Nazianze, Louvain, 1966, p. 78

${ }^{6} \mathrm{~J}$. Bernardi, op. cit., Introduction, p. 57.

${ }^{7}$ Luciano, Diálogo 59, 7

${ }^{8}$ Orat. IV, 20, 3

${ }^{9}$ Orat. V, 42

${ }^{10}$ U. Criscuolo, «Gregorio di Nazianzo e Giuliano», AA.VV. (eds.), Talariskos. Studia Graeca Antonio Garzia sexagenario oblata, Napoli 1987, p.177.

${ }^{11}$ Orat. IV, 1
} 
Escucha, alma del gran Constancio...; escuchad vosotros, reyes todos amigos de Cristo que le habéis precedido, pero, por encima de todos, tú. Después de haber aumentado su poder (del Imperio) al tiempo que extendía la herencia de Cristo cuanto le fue posible, después de haber consolidado esta herencia hasta el punto de convertirse por ello en el más famoso de los emperadores de todos los tiempos, cometió, por desgracia, un error indigno de su piedad ${ }^{12}$.

Es así como, ya de entrada, Constancio es contrapuesto a Juliano, pero, sobre todo, santificado como el más grande de los reyes philochristianoi y, por lo tanto, implícitamente por encima del propio Constantino, para ensalzar su reinado que es elevado a la condición de modelo de régimen político cristiano ${ }^{13}$.

Este Proemio con enorme carga retórica le sirve a Gregorio para justificar el único error que atribuye a Constancio, haber nombrado heredero a Juliano, un error «indigno de su piedad (eusebeia)», que ha determinado que el reinado de Juliano deba ser visto sólo como un paréntesis peligroso en la sucesión de príncipes filocristianos, y que con un hábil artificio retórico trata de transformar en virtud: el error se debió a su exceso de «filantropía» pues «sin quererlo, nutrió para los cristianos al enemigo de Cristo y fue la única ocasión en que no ejerció bien la filantropía porque salvó e hizo reinar a aquel que le sobrevivió y reinó para desgracia de todos. Por ello él se alegrará mucho ahora al ver destruida la impiedad y reinstaurada para los cristianos la anterior situación, y se alegrará también de escuchar este discurso» ${ }^{14}$.

La Invectiva, cuyo leivmotiv es contraponer a Constancio con Juliano, alcanza su clímax oratorio en otro pasaje del discurso cuando Gregorio, recurriendo de nuevo a la figura retórica del apóstrofe, imagina que le está escuchando el propio Constancio desde el cielo y ensalza sus méritos al mismo tiempo que vuelve a justificar su error al elegir al sucesor. De este modo, lo que fue concebido como diatriba contra el Apóstata se transforma en panegírico del más cristiano de los emperadores. Después de valorar su muerte como «un daño y una desgracia para el mundo entero» porque abrió el camino al reinado de Juliano, se dirige a él en este largo lamento:

Y esto, ¿por qué, oh tú, el más divino de los emperadores y el más amante de Cristo? Me atrevo a reprocharte (el nombramiento de Juliano) como si estuvieses aquí presente y me escuchases. Soy consciente, sin embargo, que estás muy por encima de los reproches por cuanto te encuentras ya junto a Dios y eres partícipe de su gloria allá arriba y que, si nos has abandonado, es sólo para cambiar de reino (basileia). ¿Por qué tomaste esta decisión tú, que superabas en inteligencia y en perspicacia (synesei kai anchinoia) a la mayoría de los emperadores, no sólo a tus contemporáneos, sino también a los que te han precedido? Tú, que habías limpiado la tierra de los bárbaros que te rodeaban y habías sometido a los tiranos dentro de nuestro territorio, a unos

\footnotetext{
12 Orat. IV, 3

13 Vid. U. Criscuolo, op. cit., p.176

${ }^{14}$ Orat. IV, 3
} 
sólo con las palabras, a otros con las armas ${ }^{15}$. Tú, que llevabas a cabo cada una de estas acciones sin ser inquietado por los enemigos. Tú, que habías logrado grandes triunfos con las armas en el campo de batalla, pero más grandes y gloriosos sin derramar sangre. Tú, a quien acudían de todas partes embajadas y súplicas. Tú, a quien todo estaba sometido o a punto de ser sometido, y para quien cualquier deseo era como si ya lo hubiese alcanzado. Tú, a quien la mano de Dios guiaba en todas tus decisiones y acciones. Tú, en quien no se sabe si admirar más la fuerza o la inteligencia y, por encima del prestigio en una y otra, la piedad (eusebeia $)^{16}$.

En esta exaltación de las hazañas y virtudes, la considerada más importante, la eusebeia, sinónimo en el leguaje eclesiástico del momento de ortodoxia ${ }^{17}$, se asocia estrechamente en la pluma del rétor capadocio con otra virtud de gran raigambre en la tradición política clásica, la filantropía, cuyo exceso le sirve para justificar el único error reprochable al cristiano emperador, haber elegido a Juliano como colega. Una virtud, la filantropía, que no deja de tener un profundo significado en el discurso, puesto que Juliano había hecho de ella la principal virtud del basileus y el banco de prueba del helenismo por él patrocinado ${ }^{18}$. Para expresarlo, Gregorio recurre a una figura retórica, un oxímoron, difícilmente traducible al español, inhumana filantropía, en un pasaje donde explaya todas las capacidades oratorias que le ofrecía su juventud:

Pero, ¿cómo se explica que sólo en esta acción te hayas mostrado torpe e inexperto? ¿Por qué aquella precipitación de tu inhumana filantropía (apanthropou philanthropias)? ¿Qué demonio se introdujo en tu mente? ¿Cómo fue posible que entregases de golpe, en tan breve tiempo, en un instante, a nuestro común verdugo, esta gran herencia, orgullo de tu padre, quiero decir, aquellos que llevan el nombre de Cristo, este pueblo que ha iluminado por doquier a todo el mundo habitado, este sacerdocio regio que ha crecido entre tantas dificultades y con tanto esfuerzo ${ }^{19}$.

La gran invectiva antijulianea que constituyen las Orationes IV y V de Gregorio de Nacianzo se convirtió por exigencias del arte de la retórica en una synkrisis, una antítesis o contraposición entre las figuras de Constancio y Juliano, que desemboca inevitablemente en un panegírico u oración fúnebre del primero. Un panegírico en el que, siguiendo las normas tradicionales del género (basilikos logos), la realidad histórica que,

\footnotetext{
15 Alusión a los usurpadores a los que tuvo que hacer frente Constancio: Silvano y Vetranión fueron sometidos sin recurrir a las armas; Magnencio fue derrotado en la batalla de Mursa en el 351.

16 Orat. IV, 34

17 Vid. J. Bouffartigue, «Entre Constantin et Théodose. L'image incertaine des empereurs chrétiens chez leurs coreligionaires des IV et V siècles», Les Études Classiques 75 (2007), p.55: le bon empereur, celui qui attire sur l'Empire romain la bénédiction du ciel et qui mérite louange et actions de grâces, se définit par une vertú essentielle: la pieté.

18 Sobre la filantropía de Juliano, vid. el clásico estudio de J. Kabiersch, Untersuchungen zum Begriff der Philantropia bei dem Kaiser Julian, Wiesbaden, 1960.

19 Orat. IV, 35; sobre la contraposición philantropia-apantropia vid. et. Orat. IV, 90,1
} 
por su proximidad cronológica el Nacianzeno conocía perfectamente, es deformada en profundidad para ensalzar la figura del homenajeado, que no es más que el contrapunto del vituperado Juliano a lo largo de toda la obra ${ }^{20}$. En este tipo de fuentes literarias más que nunca el historiador y el filólogo deben superar las palabras para verificar lo que hay de retórica y de pensamiento personal del autor. Por ello, no puede dejar de sorprender la imagen que Gregorio quiso transmitir a la posteridad de este emperador arriano en pasajes como el que sigue, en donde la grandeza de Roma aparece asociada a la de los emperadores cristianos. Si en los lugares anteriormente citados atribuye el error del emperador de haber depositado su confianza en Juliano a su excesiva filantropía, en éste que sigue Gregorio intenta justificar muy sutilmente la política religiosa pro-arriana de Constancio por la loable intención de alcanzar la unidad entre todos los cristianos:

Nunca tuvo un deseo más ardiente que el que mostró por ver crecer el número de los cristianos y que su gloria y su poder alcanzasen el más alto grado. Ni los pueblos sometidos, ni el buen gobierno del Imperio, ni la abundancia de riquezas, ni la difusión de su fama, ni el ser rey de reyes y llevar este título, ni todas aquellas cosas que para los hombres significan la felicidad, nada de todo esto le proporcionaba tanta alegría como que él gracias a nosotros y nosotros gracias a él nos viésemos honrados ante Dios y los hombres y su reinado permaneciese para siempre imperecedero entre nosotros. En efecto, sabía bien, porque su idea sobre estas cosas era más alta, más digna de un rey de lo que es común entre la mayoría, que la grandeza de los romanos había aumentado al mismo tiempo que la de los cristianos, que el Imperio se había iniciado con la llegada de Cristo pues nunca hasta entonces todo el poder había estado en manos de un solo hombre. Y es éste el motivo de que prestase un especial interés a nuestras cosas. $\mathrm{Y}$, al parecer, hacía bien pues, si se dio el caso de que nos causase algún daño, no es por despreciarnos o por ejercer violencia sobre nosotros (los nicenos), ni por deseo de complacer a otros en vez de a nosotros, sino para que todos fuésemos uno solo y tuviésemos un mismo pensamiento y no estuviésemos enfrentados y divididos por los cismas ${ }^{21}$.

El arrianismo de Constancio era demasiado conocido y su política religiosa antinicena demasiado reciente para que fuese ignorada y no se le reprochase por los lectores - pues parece que los discursos no fueron compuestos para ser pronunciados- esta imagen que pretende ofrecer de Constancio como modelo de emperador cristiano ${ }^{22}$. Se explica que vuelva a insistir en el tema, ofreciendo una nueva justificación, en la Ora-

\footnotetext{
${ }^{20}$ Se podría, y creo que no se ha hecho nunca, reconstruir este panegírico de Constancio, implícito en las dos invectivas, y establecer una comparación con los dos panegíricos (Orat. 1 y 3) que el propio Juliano compuso en honor de Constancio disimulando sus verdaderos sentimientos que sí se desvelarán posteriormente en su famoso Misopogon.

21 Orat. IV, 37

${ }^{22}$ Es cierto que sus creencias responden a lo que se suele denominar un arrianismo moderado (vid., entre otros, Teodoreto, H.E. III, 3; Sozomeno, H.E. III,18,4) pero no comparto la sorprendente afirmación de J. Bouffartigue, op.cit., pp. 57-58 de que, cuando Gregorio escribe este Discurso, no se había difundido su política
} 
tio $\mathrm{V}$ en un pasaje que es también un modelo de habilidad retórica. Aquí, después de describir la apoteosis cristiana y los funerales de Constancio, el orador capadocio descarga la responsabilidad de su política religiosa en los errores de los obispos y de los colaboradores que abusaron de la buena fe y la piedad no consolidada del emperador. Y no sólo eso. Gregorio ensalza el hecho de ser el sucesor de su padre, que le había dejado como la mejor herencia la fe cristiana, el haber reinado con justicia y haber tenido una muerte santa. ¿Qué más méritos se podían atribuir al antecesor de Juliano? Así se expresa el Nacianzeno:

En efecto, si da la impresión de que atacó la fe ortodoxa, también de este reproche se debe hacer responsables a la ignorancia y errónea doctrina de quienes de él dependían, que se aprovecharon de su espíritu simple y de su fe no consolidada, para, inconsciente de los peligros, llevarlo a donde ellos querían y, bajo el pretexto de rigor, indujeron su celo al mal. Pero nosotros, con el pensamiento puesto en su padre, que había proporcionado al cristianismo el soporte de su poder imperial y de su fe, honramos como es debido los despojos de quien ha reinado con justicia durante su vida, ha terminado santamente su existencia y nos ha transmitido el poder ${ }^{23}$.

Como en toda Oración fúnebre, y repito que así deben ser consideradas en honor de Constancio también las dos Invectivas antijulianeas de Gregorio, las normas de género exigían culminar con los honores atribuidos a los despojos de la persona fallecida. Si se trataba de un emperador, como en este caso, con su deificación y su consecratio. A partir de Constantino, los pensadores cristianos mostraron pocos escrúpulos para adaptar a la nueva fe esta tradición tan arraigada en el paganismo romano. G. Bonamente ha hablado a este respecto de santificación frente al concepto tradicional de divinización ${ }^{24}$. Aunque no faltaron críticas, tanto por parte pagana como cristiana, a esta pervivencia del culto imperial entre los cristianos. Se da la circunstancia de que S. Agustín y el contemporáneo autor anónimo de las Consultationes Zacchei et Apollonii recurren a argumentos muy similares para justificarlo. Agustín lo considera un exceso de adulación hacia el emperador difunto,

antinicena: la réputation de Constance comme empereur hostile aux ortodoxes et donc malfaisant n'est pas encore établi au moment où, vers 354 (errata por 364) Grégoire redige ses discours. Esto supone ignorar todas las diatribas contra el hijo de Constantino de Hilario de Poitiers y Lucifer de Cagliari, entre otros.

${ }^{23}$ Orat. V, 16,4-17,1. Este pasaje no aparece en algunos manuscritos, lo que ha inducido a su editor, J. Bernardi, a lanzar la hipótesis de que fuese censurado por algún copista escandalizado de que Gregorio justificase el arrianismo de Constancio: l'indulgence de l'auteur pour le protecteur de l'arrianisme et le persécuteur de l'ortodoxie q'avait été Constance a visiblement fait l'objet d'une censure de la part d'un copiste scandalisé, vid. op. cit., Introd., p. 69; para otras posibles interpretaciones, vid. L. Lugaresi, Gregorio di Nazianzo, La morte di Giuliano l'Apostata: Orazione V, Firenze 1997, n. al texto, pp. 287-208, quien, a su vez, remite a J. Mossay, op. cit. pp. 383-384.

${ }^{24}$ Vid. G. Bonamente, «Dall'imperatore divinizato all'imperatore santo», P. Brown-R. Lizzi Testa (eds), Pagans and Christians in the Roman Empire: The Breaking of a Dialogue (IV-VI Century A.D.). Procedings of the International Conference at the Monastery of Bose (October 2008), Wien-Berlin 2011, pp. 339-370, esp. pp. 344-345; G. Ventura da Silva, Reis, santos e feticeiros. Constâncio II e os fundamentos místicos da basileia 337-361, esp. cap. III: «A realeza sagrada», Vitoria (Brasil), 2003, pp. 99-159. 
pero no un error de naturaleza teológica: mortuum Romulum [...] in deos rettulere Romani [...] nec postea nisi adulando, non errando, factum est temporibus Caesarum ${ }^{25}$. Por su parte, el Anónimo reconoce que existen excesos cometidos por el pueblo; se trata, añade, de una publica adoratio cuyo origen era la adulación al emperador (adulatio homines impulit), pero que se ha convertido en una costumbre y muchos, llevados de la emoción que experimentan ante las imágenes de los emperadores, hacen más de lo que los propios emperadores exigen. Por ello, el autor lo califica, no de culto divino sino como homenaje imprudente (incautum obsequium ... officia incautiora) para terminar con esta discutible afirmación: non tamen deus dicitur, cuius efigies salutatur ${ }^{26}$.

Gregorio, como buen conocedor que era de las pautas marcadas por el rétor Menandro, dedica en la Oratio V un largo pasaje a los funerales de Constancio comparándolos, como era inevitable, con los que le habían sido tributados, veintiún meses después, a Juliano. Se trata de una nueva synkrisis con que se propone establecer el contraste, no sólo entre el diverso final de uno y otro en este mundo, sino también con la aprobación o la condena divinas en la otra vida. El largo pasaje que Gregorio dedica a estos funerales ha sido objeto de numerosos comentarios, pues constituye uno de los textos que mejor reflejan los esfuerzos de la Iglesia constantiniana por utilizar con fines apologéticos una institución tan romana y anticristiana por sus orígenes como la Apoteosis imperial, y porque también es una prueba de cómo unos funerales, que se presentan como cristianos, no hacen sino adaptar a las nuevas circunstancias el modelo tradicional romano ${ }^{27}$. Estos pasajes del Nacianzeno podrían ser considerados la culminación de lo que he denominado oración fúnebre de Constancio, quien, muerto el 3 de noviembre del 361 en Cilicia, fue transportado solemnemente para ser inhumado en Constantinopla junto a su padre, Constantino. Gregorio dice que a la llegada del féretro a la Capital Imperial se oyeron desde las alturas voces angelicales, que parecen evocar el pasaje de Lucas sobre el nacimiento de Jesús. Justin Mossay ha resumido muy bien la descripción del Nacianzeno cuando califica este pasaje como le plaidoyer d'un partisan de Constance pour l'ortodoxie du Prince añadiendo que l'adjectif angélique emprunté à l'imagerie traditionelle, associe chants des psaumes, cortèges monastiques, liturgies de l'autre monde dans une polysémie qui ne précise pas les faits, mais qui garantit leur orthodoxie ${ }^{28}$. Pero pasemos a las palabras de Gregorio, que merecen una comparación con la descripción de los funerales de Constantino que, como recordó Eusebio de Cesarea, habían sido presididos por «el joven emperador Constancio, que cumplió lo que la

\footnotetext{
${ }^{25}$ Agustín, De civitate Dei 18,24

${ }^{26}$ Consultationes I, 28, 1-8: nótese que el autor se sirve del término salutatur en vez de adoratur

${ }^{27}$ Vid. J. Mossay, op. cit, pp. 210-228; J. Arce, «Los funerales del emperador Constancio II (a. 361 d.C.)», Homenaje al prof. F. Rodríguez Adrados, Madrid, 1987, pp. 29-39; Idem, Funus imperatorum. Los funerales de los emperadores romanos, Madrid, 1988, pp. 29-30; sobre los funerales de los emperadores del s. IV en general, St. Rebenich, «Von dreizehnten Gott zum dreizehnten Apostel? Der tote Kaiser in der Spätantike», H. Schlange-Schöningen (ed.), Konstantin und das Christentum, Darmstadt, 2007, pp. 216-244.

28 J. Mosay, op. cit., pp. 394 y 399
} 
piedad filial demanda tributando al padre el merecido agasajo, tanto por el hecho de su presencia como por el ceremonial que en su honra se desplegó» ${ }^{29}$. Así se expresa Gregorio:

Puesto que también nosotros poseemos un cadáver, el de su predecesor (Constancio), veamos también lo que ha diferenciado a los dos emperadores, si es que esto puede servir a la felicidad o a la desgracia de ambos desaparecidos. El del primero es acompañado de alabanzas de todo el pueblo, llevado en cortejo acompañado por nuestros sagrados ritos, es decir, velado durante toda la noche con los cánticos y luminarias de antorchas con que nosotros, los cristianos, acostumbramos a dar una despedida piadosa. El transporte fúnebre de su cuerpo constituyó una solemne asamblea del pueblo afligido. Si hemos de dar fe a las crónicas, corrió por doquier la voz de que, cuando el cuerpo cruzó el Tauro para ir a reposar en la ciudad de su padre, en la ciudad que lleva su nombre, y que es un nombre grande (el de Constantino), muchos escucharon sonidos que provenían de las alturas similares a las de un cortejo entonando salmos. Se trataba, al parecer de potencias angélicas que rendían este honor y homenaje fúnebre a la piedad imperial ${ }^{30}$.

Sigue el pasaje anteriormente citado, en donde Gregorio justifica la fe equivocada del emperador y recuerda su santa muerte ${ }^{31}$ para proceder después a la descripción muy gráfica de la entrada del féretro en la ciudad. Recuerda el polemista Gregorio la presencia de Juliano en el acto, pero, a diferencia de Constancio en los funerales de su padre, atribuye su presencia al hecho de haber sido obligado a ello por los soldados del ejército:

¿Cómo describir, a medida que se acercaba a la gran ciudad imperial, la escolta por parte de todo el ejército, las filas de los soldados en armas en honor del emperador, como si estuviese en vida, y la multitud de los habitantes de aquella magnífica ciudad, tan memorable como nunca lo había sido o lo será en el futuro? Pero el otro (Juliano), orgulloso de sí mismo y de la púrpura nueva y por ello, me parece, lleno de soberbia, participa también en la ceremonia fúnebre dando y recibiendo los mismos honores. Se dice que éstos los concedía por obligación y los recibía con placer. En efecto, todo el ejército, a pesar de la sumisión al nuevo poder, manifestaba un respeto más profundo por el difunto, puesto que, por naturaleza somos más propensos a sentir más los dolores recientes. Los soldados estaban dominados por el afecto y la piedad que sentían por él y por eso no soportaron que no fuese honrado como un emperador, y obligaron al apóstata a acogerlo como tal y le forzaron a salir al encuentro del cadáver con la vestimenta apropiada, a saber, con la cabeza despojada de la diadema e inclinada ante el emperador como convenía, y a acompañar así al cortejo hasta la tumba, hasta ese célebre santuario donde los Apóstoles han

\footnotetext{
${ }^{29}$ Eusebio, Vita Constantini IV, 70.

${ }^{30}$ Orat. V, 16, 1-3

${ }^{31}$ Orat. V, 16,4-17,1.
} 
acogido y siguen acogiendo la sagrada estirpe (constantiniana) que goza casi de los mismos honores que el santuario ${ }^{32}$.

Es llamativa la tendenciosidad de la narración de Gregorio, que presenta a Juliano acudiendo a recibir el cuerpo de Constancio obligado por los soldados, en contraste no sólo con lo que dice Eusebio que éste había hecho con su padre, sino también frente a las versiones de la publicidad pagana contemporánea. Así Libanio, que lo atribuye a un gesto espontáneo impulsado por unos sentimientos sinceros, a pesar de las diferencias religiosas entre ambos. En cualquier caso, resulta difícil discernir si la deformación histórica es mayor en el rétor pagano o en el cristiano: «Y no se detuvo aquí su respeto hacia el finado, sino que bajó al puerto de la gran ciudad, después de haber congregado al pueblo en su totalidad, y lloraba mientras el cuerpo era transportado aún por el mar. Se aferraba al féretro con las manos después de haber depuesto todas las insignias reales, a excepción de su clámide, porque no consideraba justo culpar al cuerpo de los designios de su alma ${ }^{33}$.

Sirviéndose, una vez más, de un recurso retórico muy efectista, Gregorio hace preceder la descripción del entierro de Juliano en Tarso con el recuerdo de los desprecios de que sabemos había sido objeto el emperador en Antioquía, antes de partir para el frente persa donde perdería la vida, para resaltar que, «si la partida había sido vergonzosa $[. .$.$] su retorno fue aún mas ignominioso» { }^{34}$. Añade a continuación que, en vez de ser acompañado el cadáver por los soldados y el pueblo, como fue el caso de Constancio, fue llevado al sepulcro rodeado de mimos de comedia y entre las burlas del pueblo:

Actores cómicos formaban su cortejo con las infamias propias de su repertorio, entre sonidos de flautas y danzas lascivas mientras le echaban en cara su apostasía, su derrota y su final. ¿Qué ultraje no sufrió, qué insultos no escuchó de aquellos que se comportan con insolencia hasta que llegó a la ciudad de Tarso que se vio condenada, yo no sé cómo y porqué a sufrir esta humillación? Fue allí donde recibió una morada deshonrosa, una tumba maldita, un templo infame, que no es merecedor ni siquiera de las miradas de las personas piadosas ${ }^{35}$.

Esta denigración caricaturesca de los funerales de Juliano pretendía quizá también, como ha sugerido Leonardo Lugaresi, prevenir el peligro inherente a un culto post mor-

\footnotetext{
32 Orat. V, 17, 2-5; sobre la Iglesia de los Santos Apóstoles, mandada construir por Constantino como mausoleo imperial, rodeado, cual isapostolos, de los cenotafios de los doce Apóstoles, Eusebio, Vita Constantini IV, 58-60; vid. J. Arce, op. cit., pp. 110-116.

${ }^{33}$ Libanio, Oratio XVIII, 120; por lo demás, el despojarse de la diadema en tales ocasiones parece que formaba parte del ceremonial cortesano: vid. S. MacCormack, Art and Ceremony in Late Antiquity, BerkeleyLos Angeles, 1981, p. 330, n. 198; llama la atención que Amiano Marcelino, que describe los funerales, no mencione la presencia de Juliano, recordada por otros autores paganos y cristianos: Amiano, XXI, 16,20-21; Mamertino, Grat. Act. 27,5; Filostorgio 6, 6ª -7á; Sócrates 3, 1.

${ }^{34}$ Orat. V, 18,1

35 Orat. V, 18,1-2
} 
tem, promovido en los ambientes paganos por sus admiradores ${ }^{36}$. Un culto del que se hace eco el propio Gregorio cuando critica a aquellos que «veneran las empresas de ese hombre y lo representan como un nuevo dios, dulce y filántropo» ${ }^{37}$. Alude también a ello en la Oratio V cuando, al describir la muerte del emperador en el campo de bata1la, dice que, sintiéndose a punto de morir, quiso arrojarse al Eúfrates para después poder ser venerado como un neos theos ${ }^{38}$. En cualquier caso, es evidente que esta contraposición entre la memoria de ambos emperadores ocupa un lugar privilegiado en el marco de la fuerte polémica apologética que rodeó la muerte de Juliano. Testimonio privilegiado del culto a Juliano es Libanio, quien dedicó al emperador difunto el citado discurso fúnebre (el XVIII de su corpus), un verdadero enkomion del desaparecido emperador, donde repasa toda su vida antes y después de su ascenso al trono. Como exigía este género literario, hay un pasaje dedicado a la Apoteosis del emperador y a la veneración de que en muchos lugares fue objeto el emperador divinizado desde el momento de su muerte como un attivo wonder-worker, por servirme de la expresión de Lelia Cracco Ruggini: «Ya que hice mención de imágenes, numerosas ciudades le han situado en las moradas de los dioses y como a un dios lo veneran. Y hay quien le pidió con súplicas algún beneficio y no dejó de lograr su objetivo. Con tanta naturalidad ha ascendido para reunirse con aquellos, y compartido junto a los propios dioses su poder divino» ${ }^{39}$.

Aunque el discurso de Libanio es posterior a las invectivas de Gregorio, resulta significativo comparar su Apoteosis pagana de Juliano con la cristiana de Constancio y las escasas diferencias existentes entre una y otra: quizá la más significativa es que Gregorio, a pesar de situar al emperador en la gloria, junto a Dios, no le atribuye un culto ni la realización de milagros, aunque L. Lugaresi sugiere que la expresión «como si estuviese vivo» $(O r . \mathrm{V}, 17,2)$ tal vez haga referencia a las capacidades sobrenaturales de los cuerpos de los difuntos, de acuerdo con creencias compartidas en la época por paganos y cristianos y que constituyeron el fundamento del culto de los mártires $\mathrm{y}$ de los santos en general ${ }^{40}$.

G. Bonamente, en el documentado estudio ya mencionado, ha llevado a cabo el análisis del proceso que en el siglo IV, desde Constantino a Teodosio, llevó a los cristianos a elaborar el nuevo modelo sobre el destino de los emperadores buenos después de su muerte y que conllevó la substitución de la divinización por la santificación, es decir, al emperador divinizado por el emperador santo. El estudioso italiano ve la mejor plasmación de este proceso en la oración fúnebre De obitu Theodosii, que Ambrosio de Milán dedicó a Teodosio I en el 395, donde le presenta disfrutando en el cielo de la pre-

\footnotetext{
36 L. Lugaresi, op. cit., 1997, Introd., pp. 64-68.

37 Orat. IV, 94,1

${ }^{38}$ Orat. V, 14, 3: subyace aquí el recuerdo de Empédocles y otros seres divinos desaparecidos de forma misteriosa o milagrosa. Puede recordarse el caso de Peregrino Proteo, satirizado por Luciano de Samosata.

${ }^{39}$ Libanio, Oratio XVIII, 304; L. Craccco Ruggini, «Imperatori e uomini divini (I-VI sec)», P. Brown-L. Cracco Ruggini- M. Mazza, (eds.), Governanti e intellettuali, popolo di Roma e popolo di Dio. I-VI secolo, Torino 1982, p.21; al tema dedicó un importante estudio A. D. Nock, «Deification and Julian», J.R.St. 47 (1957), pp.115-123; vid. et. los interesantes comentarios en U. Criscuolo, «Libanio e Giuliano», Vichiana N.S. XI, (1982), pp. 70-87, especialmente pp. 83-87; G. Bonamente, op. cit., p. 368, n.116

${ }^{40}$ L. Lugaresi, op. cit., 1997 , pp. 208-209.
} 
sencia divina en compañía de Graciano y de los miembros de su familia ya fallecidos, mientras que de los Augustos que le habían precedido sólo es mencionado Constantino. Frente a ellos aparecen los usurpadores Máximo y Eugenio, víctimas de una damnatio cristiana, es decir, colocados in inferno ${ }^{41}$. G. Bonamente califica el discurso como un'originale reflessione su un modelo sustanciamente inedito ${ }^{42}$, por lo que parece ignorar que muchos años antes Gregorio de Nacianzo había santificado ya a Constancio II en un pasaje que parece haber inspirado al propio Ambrosio. Recordaré una vez más que, después de haber honrado a Constancio con unos funerales cristianos en los que hicieron acto de presencia los ángeles del cielo, se dirige al theiotate y philochristotate emperador con este apóstrofe: «Soy consciente de que te encuentras ya junto a Dios y eres partícipe de su gloria allá arriba y que, si nos has abandonado, es sólo para cambiar de reino $\rangle^{43}$. No deja de tener un alto significado que el primer emperador al que un autor cristiano de la importancia de Gregorio de Nacianzo santificó, colocándolo en la gloria junto al trono divino, sea ignorado algunos años después por otro obispo no menos influyente como es Ambrosio de Milán. Evidentemente el motivo de este olvido no es otro que la fe arriana profesada por el hijo y sucesor de Constantino. Cuando se produjo la muerte de Teodosio las circunstancias habían cambiado y Ambrosio no tuvo necesidad de recurrir a la argucia retórica que indujo al obispo capadocio a presentar a Constancio como santo y modelo de príncipe cristiano.

Las formas y modalidades comunicativas de la retórica antigua fueron utilizadas con gran maestría, tanto por los admiradores como por los enemigos para ensalzar o denigrar la discutidísima figura de Juliano, en el marco del gran debate paganismo-cristianismo que caracterizó la segunda mitad del siglo IV. Por extensión, también se vieron implicadas en la polémica aquellas otras figuras que estuvieron en estrecho contacto con el apóstata como es el caso de Constancio II. Gregorio de Nacianzo, uno de los más eximios representantes de la denominada Tercera Sofística, no tuvo ningún escrúpulo ideológico en convertir las Invectivas contra Juliano en una Laudatio fúnebre del philochristós emperador arriano Constancio, llevado de la necesidad impuesta por las leyes de la retórica de oponer en perfecta synkrisis la personalidad de éste a todo lo que Juliano había representado. Como ha escrito J. Bernardi, plus l'empereur païen est décrié, plus le souverain chrétien doit être rendu par la synkrisis digne d'admiration ${ }^{44}$.

Gregorio de Nacianzo fue uno de los más hábiles rétores que conoció la Antigüedad, y me atrevo a concluir este ensayo dirigiéndole a él la invocación con que Libanio terminó su Oración Fúnebre en honor de Juliano: «iOh tú, que pisoteaste todos los placeres salvo los de la retórica! Éste es el homenaje de nuestra humilde elocuencia, que tú solías considerar importante» ${ }^{45}$.

\footnotetext{
${ }^{41}$ Ambrosio Milán, De obitu Theodosii 39, 51-52; G. Bonamente, op. cit., pp. 351-356 y 369-370.

42 Ibid. p. 352

${ }^{43}$ Orat. IV, 34, 1.

${ }^{44}$ J. Bernardi, op. cit., Introduction, p. 61; el mismo autor señala con acierto que no menos sorprendente que el elogio de Constancio es el del obispo Marcos de Aretusa dont des témoinages irréfutables attestent les liasons avec les ariens, ibid. p. 31

45 Libanio, Oratio XVIII, 308.
} 